\title{
Epidemiology of Opisthorchis viverrini in a rural district of southern Lao PDR
}

\section{Somphou Sayasone ${ }^{a, b}$, Peter Odermatt ${ }^{a, b, *}$, Niranh Phoumindr ${ }^{a, c}$, Xaybundith Vongsaravane ${ }^{d}$, Viensene Sensombath ${ }^{a}$, Rattanaxay Phetsouvanh ${ }^{e}$, Xayadeth Choulamany $^{f}$, Michel Strobel $^{a}$}

\author{
a Institut de la Francophonie pour la Médecine Tropicale, Vientiane, Lao PDR \\ b Department of Public Health and Epidemiology, Swiss Tropical Institute, Basel, Switzerland \\ ${ }^{c}$ Faculty of Medical Sciences, National University of Laos, Vientiane, Lao PDR \\ ${ }^{\mathrm{d}}$ Mahosot Hospital, Ministry of Health, Vientiane, Lao PDR \\ e Centre of Malariology, Parasitology and Entomology, Ministry of Health, Vientiane, Lao PDR \\ ${ }^{f}$ Live Aquatic Resources and Research Centre, Ministry of Agriculture and Forestry, Vientiane, Lao PDR
}

Received 30 December 2005; received in revised form 13 February 2006; accepted 14 February 2006 Available online 7 July 2006

\section{KEYWORDS \\ Opisthorchis viverrini; \\ Food-borne \\ trematode; \\ Epidemiology; \\ Lao PDR}

\begin{abstract}
Summary In Lao PDR, detailed investigations on Opisthorchis viverrini are scarce. The objective was to document epidemiological features of $O$. viverrini infections in a highly endemic district. A random sample was selected (13 villages, 15 households/village, all household members aged $>6$ months). Clinical examinations, short interviews and stool examinations (Kato-Katz technique) were performed. Fish samples were dissected for the presence of metacercaria. In total, 814 persons were enrolled (median age 16 years, $51.5 \%$ women). The prevalence was 58.5\%. Infection rates increased with age (from 20.0 to $85.5 \% ; P<0.001$ ). Intensity of infection and the habit of consuming insufficiently cooked fish also increased with age. Of the study participants, $75.2 \%$ reported cooking fish insufficiently. Of the 23 different species of cyprinoid fish consumed in the study villages, 20 species were infected. At the village level, the prevalence of raw fish consumption was strongly associated with the infection status of $O$. viverrini $(r=0.76, P=0.003)$. At individual level, age, the consumption of insufficiently cooked fish, and the absence of sanitation were strongly associated. The disease associated with $O$. viverrini infection needs to be assessed in order to develop and conduct adequate interventions.

(c) 2006 Royal Society of Tropical Medicine and Hygiene. Published by Elsevier Ltd. All rights reserved.
\end{abstract}

\section{Introduction}

* Corresponding author. Present address: Swiss Tropical Institute, Postfach, 4002 Basel, Switzerland. Tel.: +41 6128482 14; fax: +41612848105.

E-mail address: peter.odermatt@unibas.ch (P. Odermatt).
Food-borne trematode infection is an emerging public health issue (Keiser and Utzinger, 2005). The disease is endemic in many parts of the Far East, Southeast Asia and eastern Europe and can be spread over large distances via 
infected fish (Yossepowitch et al., 2004). The main public health problem in Southeast Asia arises from infection with trematodes belonging to the family Opisthorchiidae, such as Opisthorchis viverrini, $O$. felineus and Clonorchis sinensis. An estimated 9 million people are infected with $O$. viverrini, 1.6 million with $O$. felineus and 35 million with $C$. sinensis (Lun et al., 2005; Sithithaworn and Haswell-Elkins, 2003; WHO, 1995). Clonorchis sinensis is endemic in China, Korea, Taiwan, Vietnam and Japan, and $O$. felineus is widespread in Russian Federation and eastern Europe. Opisthorchis viverrini is of public health importance in Southeast Asia, particularly in Lao People's Democratic Republic (Lao PDR) and Thailand (Sithithaworn and Haswell-Elkins, 2003).

In Lao PDR, it is estimated that over 2 million people are infected with $O$. viverrini (WHO, 1995). The parasite was first diagnosed in 1929 by Bedier and Chesneau in the cities of Thakek (Khammouane province) and Vientiane, where infection rates of 23 and $15 \%$ were found, respectively (Upatham and Viyanant, 2003). Today, the prevalence is still very high. Rim et al. (2003) recently completed a nationwide survey among schoolchildren and found infection rates often exceeding $50 \%$ in the southern provinces. Recently, Thakek still had a prevalence rate of approximately 60\% (Kobayashi et al., 2000).

Essential knowledge about $O$. viverrini infections has been gained over the last decade in Thailand where prevalence rates of 0 . viverrini vary between very low in the south and central provinces, to high towards the border with Lao PDR in the north and north east (19.3 and 15.7\%) (Sithithaworn and Haswell-Elkins, 2003; Upatham and Viyanant, 2003). In the north, the population mostly belongs to the Lao-Thai ethnic group, in which raw food consumption is common (Upatham and Viyanant, 2003).

The adult $O$. viverrini parasite causes hepatobiliar disease. Most infections are free of symptoms (Mairiang and Mairiang, 2003). Clinical manifestations may vary from nonsevere, such as right hypochondrial pain or intestinal irrita- tion, to severe manifestation, such as cholangitis, cholecystitis and choletithiasis. Moreover, Opisthorchis infection is a main risk factor for cholangiocarcinoma (Pinlaor et al., 2004; Sriamporn et al., 2004). North east Thailand has the highest prevalence of cholangiocarcinoma worldwide (Pinlaor et al., 2004). Over $60 \%$ of cancers are attributed to 0 . viverrini (Honjo et al., 2005).

The life cycle of $O$. viverrini involves two intermediate hosts: a freshwater snail of the genus Bithynia (Sadun, 1955) and then a cyprinoid fish species host (Haswell-Elkins et al., 1992). The adult parasite lives in the biliary ducts. Eggs are shed with the faeces. Transmission of the parasite occurs when sanitation is inadequate, outdoor defecation occurs and raw fish is consumed.

The aim of the present study was to describe epidemiological features of $O$. viverrini in a highly endemic district of Lao PDR. Hence, a cross-sectional household survey was carried out in order to elucidate determinants of disease and transmission relevant for subsequent intervention.

\section{Materials and methods}

\subsection{Study setting}

The survey was conducted in the Saravane district, province of Saravane, southern Lao PDR (Figure 1), where recently a high prevalence of $O$. viverrini was found among schoolchildren (Rim et al., 2003). The province has a population of approximately $318100 ; 20 \%$ are children under 5 years of age. The birth rate and mortality rate in this province are 39.8 and 8.3 per 1000 people per year, respectively. Only $61.9 \%$ have access to safe drinking water, and as few as $15.1 \%$ have sanitary facilities in the households (NSC, 2003; PHO, 2002). Saravane district is located in the low plain and has an estimated population of 83000 people inhabiting 168 villages. Of the population, $65.0 \%$ belong to the Lao-Theung

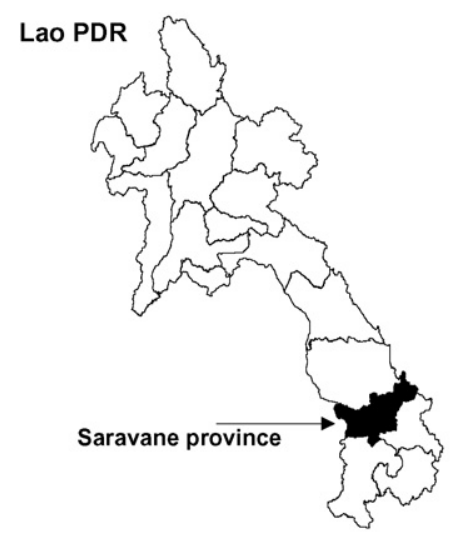

Saravane District

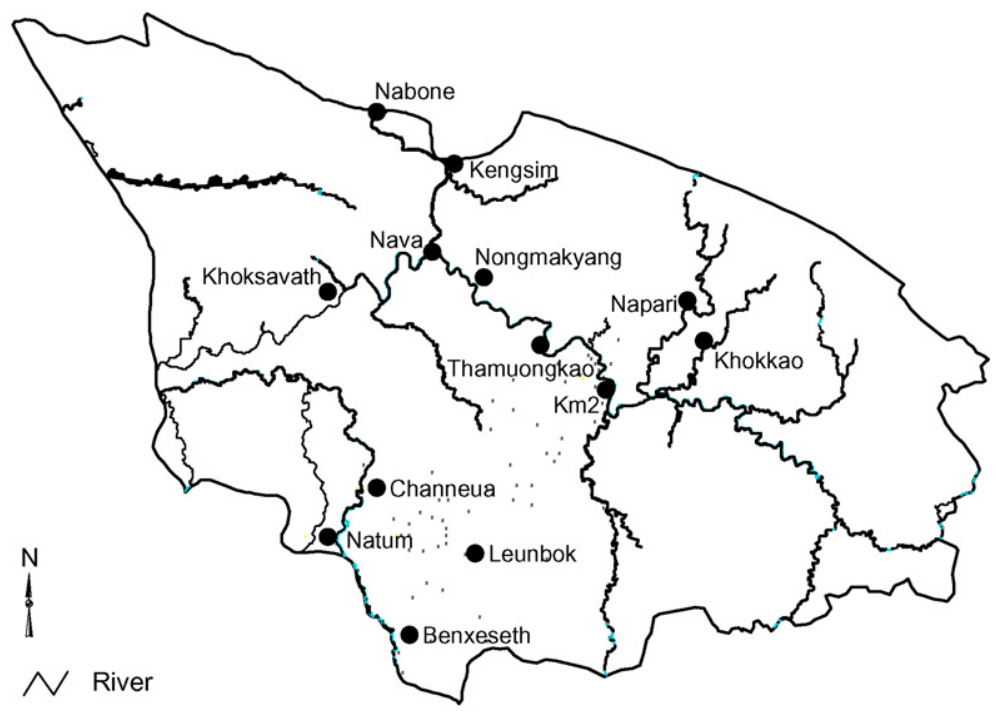

$\begin{array}{r}0 \quad 8 \quad 16 \\ \hline\end{array}$

Figure 1 Map of Lao PDR and Saravane district. 
ethnic group (PHO, 2002). The district has a main river (Xedone) with five important tributaries (Xeseth, Xekhone, Huay-pao, Hauy-pa-ae and Hauy-sleng). All are extensively used for fishing. On the Xeseth River, the second largest dam in Lao PDR has been constructed. The Xeset Hydropower Plant is a run-of-river scheme utilizing about $1.5 \mathrm{~km}$ of the river, with a drop of $157 \mathrm{~m}$. The plant provides electricity for the southern provinces of Lao PDR and Thailand and feeds local irrigation systems.

\subsection{Study design and population surveyed}

A cross-sectional study was carried out in February and March 2004. Households were selected by two-stage random sampling. First, 13 villages were selected from the list of villages at the District Health Office. Second, in each village, 15 households were selected from the list of households provided by the head of the village. All members of the selected households older than 6 months and present on the survey day were enrolled in the study.

Ethical approval was obtained from the Ministry of Health, Lao PDR. Informed consent was obtained from all authorities involved and from each individual before enrolment.

\subsection{Field and laboratory investigation}

Each study participant underwent a short clinical examination by a general physician and was interviewed on sociodemographic factors and other potential risk factors for 0 . viverrini infection. Age, level of education, profession, use of sanitary household facilities and food (habit of eating raw or insufficiently cooked fish) and personal hygiene were taken for each person. Availability of toilets or latrines and information on food preparing habits were obtained by interviewing the head of the household. Parents or caretakers were interviewed for children under 10 years of age.

A stool sample was obtained from each individual. A single (42 mg) Kato-Katz thick smear was prepared on microscope slides and examined with a light microscope for the presence of intestinal parasites (Katz et al., 1972). Opisthorchis viverrini egg counts were obtained for each sample. The presence or absence of Ascaris lumbricoides, Trichuris trichiura, Taenia spp., hookworms and other parasites was also recorded.

In each village, a fisherman was interviewed on the availability of fish and fish species in the village using a pre-tested questionnaire. A picture manual of local fish species of Lao PDR edited by the Live Aquatic Resources and Research Centre (Vientiane, Lao PDR) was used to identify fish species.

In each village, a sample of available fish species was obtained and dissected into small scraps, pressed under a cover slide and examined for the presence of trematode metacercaria using a light microscope (Rhee et al., 1983).

\subsection{Data management and statistical analysis}

All data were entered in EpiData, v. 3.01 (www.epidata.dk). Analysis was performed using STATA, version 8 (Stata Corp., College Station, TX, USA). The study participants were sub- divided into seven age groups: (1) <6 years; (2) 6-15 years; (3) 16-25 years; (4) 26-35 years; (5) 36-45 years; (6) 46-55 years; and (7) $>55$ years. Prevalence rates were used to assess helminth infections and risk factors. Student's $t$ test and $\chi^{2}$ text were used to compare means and proportions, respectively. Geometric mean of egg counts with $O$. viverrini was calculated for infected persons. Opisthorchis viverrini-positive individuals were grouped into three categories: light infections (1-999 eggs per gram of faeces [epg]); moderate infections (1000-9999 epg); and heavy infections $(\geq 10,000 \mathrm{epg})$ according to a classification proposed by Maleewong et al. (1992). Associations between $O$. viverrini infection and risk factors were performed on grouped data at village level and at individual level. Simple logistic regression was used to assess the bivariate relationship between the prevalence of $O$. viverrini infection and the prevalence of risk factors. Multivariate logistic regression was applied to relate 0 . viverrini infection and risk factors at an individual level. The following predictors were included in the regression model: age, sex, habit of eating raw or insufficiently cooked fish, availability of a latrine at home and educational level of head of households. Where appropriate, $95 \% \mathrm{Cl}$ are provided.

\section{Results}

\subsection{Study population}

A total of 814 persons from 157 households and 13 villages were investigated. Of these, 63.0\% (513) and 34.8\% (283) were ethnic Laoloum and Laotheung, respectively; $51.5 \%$ (419) were females (sex ratio M/F: 0.94); and 18.9\% (159) were children below 6 years of age. Age ranged from 6 months to 98 years, with a median age of 16 years. The average number of people per household enrolled was 5.2.

Among the 157 heads of households, $69.4 \%$ were male (Table 1$)$. The median age was 43.0 years $(45.0$ years for males and 39.0 years for females, $P=0.01$ ). Almost all heads of household were married (86.6\%), and their illiteracy rate was $31.2 \%$. The illiteracy rate of women was two-fold higher than that of males $(47.9$ vs. $23.9 \%, P=0.001)$. Subsistence farming was the main occupation of most heads of households $(91.7 \%)$, while very few were government employees $(1.9 \%)$ or traders $(1.9 \%)$.

\subsection{Sanitation facilities}

In only one village, closest to the provincial capital, were sanitation facilities available (Table 2). Of all study participants, 94.9\% (773 of 814) reported defecating regularly outdoors. Of these, 95.2\% defecated in the bush surrounding their village; $4.3 \%$ used a dugout hole; and $0.5 \%$ defecated into a river.

\subsection{Clinical examination}

A physical abnormality was diagnosed in 192 (23.6\%) study participants: $91(47.4 \%)$ and $31(16.2 \%)$ reported a diarrhoeal episode (more than three bowel movements within $24 \mathrm{~h}$ ) in the past week or weight loss, respectively; 30 people 
Table 1 Characteristics of studied head of households $(n=157)$

\begin{tabular}{lccc}
\hline & Total $(n=157)$ & Male $(n=109)$ & Female $(n=48)$ \\
\hline Age (years) & & & \\
$\quad$ Median & 43.0 & 45.0 & 39.0 \\
$\quad$ Age range & $18.0-81.0$ & $25.0-81.0$ & $18.0-81.0$ \\
Ethnic group, \% (95\% Cl) & & & \\
$\quad$ Laoloum & $61.1(53.1-68.8)$ & $66.1(56.4-74.9)$ & $50.0(35.2-64.8)$ \\
$\quad$ Laotheung & $38.9(31.2-46.9)$ & $33.9(25.1-43.6)$ & $50.0(35.2-64.8)$ \\
Education, \% $(95 \% \mathrm{Cl})$ & & & \\
Illiterate & $31.2(24.1-39.1)$ & $23.9(16.2-33.0)$ & $47.9(33.3-62.8)$ \\
Primary school & $56.1(47.9-64.0)$ & $61.5(51.7-70.6)$ & $43.8(29.5-58.8)$ \\
$\quad$ Secondary school & $11.5(6.9-17.5)$ & $13.8(7.9-21.7)$ & $6.3(1.3-17.2)$ \\
$\quad$ University & $1.3(0.2-4.5)$ & $0.9(<0.1-5.0)$ & $2.1(<0.1-11.1)$ \\
Profession, \% (95\% Cl) & & & \\
$\quad$ No work & $4.5(1.8-9.0)$ & $3.7(1.0-9.1)$ & $6.3(1.3-17.2)$ \\
$\quad$ Farmer & $91.7(86.3-95.5)$ & $90.8(83.8-95.5)$ & $93.8(82.8-98.7)$ \\
$\quad$ Trader & $1.9(0.4-5.5)$ & $2.8(0.6-7.8)$ & 0 \\
$\quad$ Government employee & $1.9(0.4-5.5)$ & $2.8(0.6-7.8)$ & 0 \\
\hline
\end{tabular}

(15.6\%) had a skin eruption and 22 (11.5\%) had chronic itching (chronic urticaria); 16 people $(8.3 \%)$ had clinical anaemia (sub-conjunctiva pallor); and two patients (1.0\%) had subicterus and hepatomegaly.

\subsection{Stool sample analysis}

The prevalence rates of intestinal parasitic infections are given in Table 2 . The most prevalent parasite infection was 0 . viverrini, found in more than half of the study participants (58.5\%). This infection was prevalent in all villages, ranging from 14.3 to $79.9 \%$. Benxeseth (14.3\%) and $\mathrm{Km} 2(26.7 \%)$, two villages close to the district capital, had the lowest prevalence rates. Infection rates increased with age and reached a plateau in the 16-25 years age group (Figure 2) and did not differ between gender (male 59.5 vs. female $57.5 \%, P=0.570$ ).

Of all 0 . viverrini-infected subjects (476 individuals), 92.5\% had an infection that was classified as light, $7.3 \%$ moderate, and $0.2 \%$ heavy. The geometric mean infection intensity was 154.3 (range 24-15552 epg). There was no statistical difference between males (172.3 epg) and females (138.6 epg; $P=0.357$ ). The intensity of infection increased with age in a way comparable to prevalence of infection (Figure 2). The pre-school children (aged $<6$ years) had the lowest intensity of infection (90.7 epg), while the highest was found in adults aged $45-55$ years (206.6 epg).

We found hookworm infections in $46.1 \%$ of subjects. The highest prevalence at village level reached $79.6 \%$

Table 2 Prevalence of intestinal parasites and selected risk factors by village $(n=814)$

\begin{tabular}{|c|c|c|c|c|c|c|c|c|}
\hline Village & O. viverrini & Hookworm & A. lumbricoides & T. trichiura & $\begin{array}{l}\text { Taenia } \\
\text { spp. }\end{array}$ & $\begin{array}{l}\text { Habit of } \\
\text { eating raw or } \\
\text { insufficiently } \\
\text { cooked fish }\end{array}$ & $\begin{array}{l}\text { Never heard } \\
\text { about } 0 . \\
\text { viverrini }\end{array}$ & $\begin{array}{l}\text { Availability } \\
\text { of toilet at } \\
\text { home }\end{array}$ \\
\hline Kengsim & 79.7 & 29.0 & 1.5 & 4.4 & 5.8 & 79.7 & 88.4 & 0.0 \\
\hline NongMakyYang & 78.3 & 43.5 & 1.5 & 5.8 & 2.9 & 87.0 & 88.4 & 0.0 \\
\hline Napari & 70.7 & 40.0 & 52.0 & 1.3 & 1.3 & 69.3 & 98.7 & 0.0 \\
\hline Nabone & 68.8 & 29.9 & 2.6 & 9.1 & 10.4 & 87.0 & 83.1 & 0.0 \\
\hline Channeua & 66.7 & 54.0 & 0.0 & 14.3 & 4.8 & 74.2 & 96.8 & 0.0 \\
\hline Thamuongkao & 62.3 & 39.1 & 0.0 & 2.9 & 10.1 & 73.9 & 66.7 & 0.0 \\
\hline Khoksavath & 59.7 & 47.4 & 1.8 & 1.8 & 0.0 & 91.2 & 71.9 & 0.0 \\
\hline Nava & 59.6 & 32.7 & 9.6 & 1.9 & 3.9 & 86.5 & 62.1 & 0.0 \\
\hline Natum & 59.5 & 52.7 & 8.1 & 4.1 & 1.4 & 86.5 & 51.9 & 0.0 \\
\hline Leunbok & 44.9 & 79.6 & 59.2 & 32.7 & 8.2 & 73.5 & 100 & 0.0 \\
\hline Khokkao & 42.4 & 55.9 & 0.0 & 1.7 & 10.2 & 50.9 & 88.1 & 0.0 \\
\hline $\mathrm{Km} 2$ & 26.7 & 40.0 & 20.0 & 11.1 & 4.4 & 62.2 & 48.8 & 70.0 \\
\hline Benxeseth & 14.3 & 67.9 & 62.5 & 66.1 & 1.8 & 44.6 & 91.1 & 0.0 \\
\hline Total & 58.5 & 46.1 & 15.7 & 11.1 & 5.0 & 75.2 & 80.5 & 4.5 \\
\hline
\end{tabular}




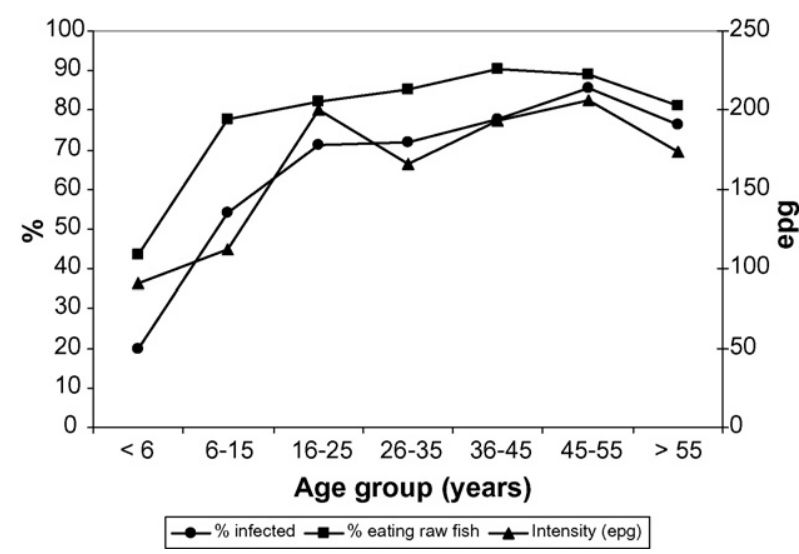

Figure 2 Prevalence (\%) and intensity (eggs per gram stool [epg]) of infection with Opisthorchis viverrini and prevalence (\%) of eating raw or insufficiently cooked fish by age.

(Table 2). Infections with $A$. lumbricoides and T. trichiura were detected in 16.0 and $11.0 \%$ of the participants, respectively. Eggs of Taenia spp. were recorded in $5.0 \%$ of the stool examinations. In three villages, the prevalence of this parasite reached $10 \%$ of the subjects.

In $83.5 \%(680 / 814)$ of the stool specimens analysed, at least one intestinal parasite species was found. One parasite species was found in $40.9 \%(333 / 814)$ of the subjects, two species in $33.1 \%(269 / 814)$, three species in $9.0 \%(73 / 814)$ and four species in $0.6 \%(5 / 814)$. The infection rates did not vary with gender ( 83.5 vs. $83.5 \%, P=0.996)$.

\subsection{Fish consumption habits}

Frequent consumption of raw or insufficiently cooked fish was reported in $75.1 \%(611 / 814)$ of people (Table 2$)$. The habit was observed in all villages, with rates between 44.6 and $91.2 \%$. Men did it significantly more frequently (79.2 vs. $71.3 \%, P=0.009$ ). The reporting rate showed a marked increase with age, paralleling infection rates (Figure 3).

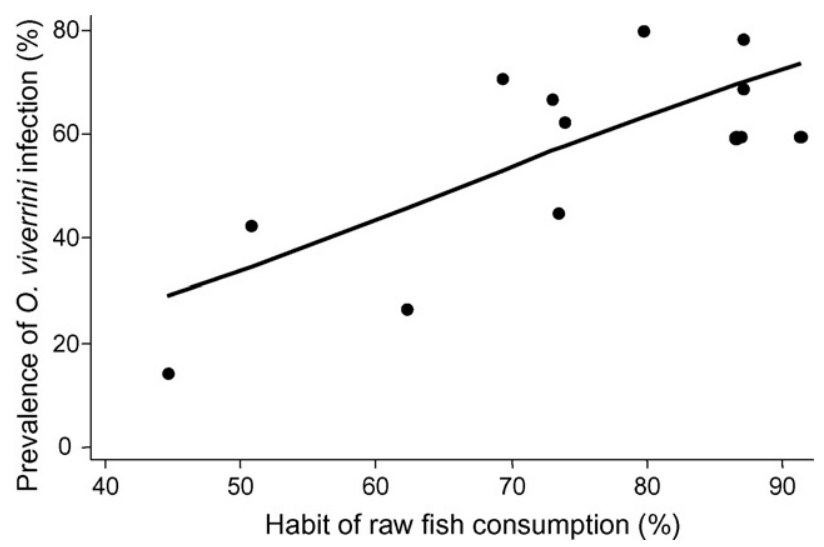

Figure 3 Association between the prevalence of Opisthorchis viverrini infection and the consumption of raw or insufficiently cooked fish at village level $(n=13)$. Two villages have very similar associations and the dots overlap. The black line represents the line of best fit.

\subsection{Fish examination}

Forty-three different fish species were found in the study villages. Of these, 23 species (53.4\%) belonged to the family Cyprinidiae. In a sample of 98 cyprinoid fishes, originating from six different rivers, metacercaria were found in 58 samples $(59.2 \%)$.

High metacercaria infection rates were found in a group of seven species. The following fish species belonged to this group (Lao name in brackets, along with number infected of number examined): Hampala macrolepidota (Pa-sout, 7 of 7), Lobocheilus melanotaen (Pa-langnam, 9 of 9), Poropuntius of laoensis (Pa-chat, 9 of 10), Puntius brevis (Pakhaomon, 6 of 7), Cyclocheilichthys enoplos (Pa-chok, 4 of 5), Oreichthys parvus Smith (Pa-siew-na, 2 of 5) and Rasbora ourotacniatiran (Pa-siew-our, 2 of 6 ).

Low metacercaria infection rates were found in a second group of 13 fish species (Lao name in brackets): Amblynchichthystrunca (Pa-tapo), Amblynchihthys truncatus (Pa-mang), Cyclocheiliehthysarmatus (Pa-dokgnue), Discherodontusahme (Pa-hangdeng), Garra fuliginosa Fowler (Pa-khome), Hypsibarbus pierrei (Pa-park), Notopterus (Patong), Osteochilus schlegeli (Pa-namoum), Osteochilus hasselti (Pa-ithai), Parachela maculicauda (Pa-tebhuabird), Puntioplites falcifer (Pa-sakang), Raiamas guyttatua (Pamitsanak-noy) and Systomus orphoides (Pa-pok).

Only three species of fish were not found to be infected (Lao name in brackets): Cyprinus carpiolinnaeus (Pa-nai), Oreochromis niloticus (Pa-nin) and Barbichthys nitibus ( $\mathrm{Pa}$ soy).

\subsection{Associations of risk factors with Opisthorchis viverrini infection}

Analysis on grouped data at village level showed a strong positive correlation between the prevalence of 0 . viverrini infection and the habit of consuming raw fish or insufficiently cooked fish ( $r=0.76, P=0.003$; Figure 3 ). No correlation was found between $O$. viverrini infection and the proportion of people who reported not having heard about opisthorchiasis $(r=0.18, P=0.564)$.

Moderate negative correlations were detected between the 0 . viverrini infection and the prevalence of hookworms ( $r=-0.57, P=0.041)$, $T$. trichiura $(r=-0.69, P=0.009)$ and $A$. lumbricoides (the latter was not significant $r=-057$, $P=0.060)$. No correlation was found with Taenia spp. infection rates $(r=0.03, P=0.918)$.

Only two cases of clinical icterus and hepatomegaly findings were clinically diagnosed. Both were infected with 0 . viverrini, one person lightly while the other was infected with moderate intensity.

In all age groups the consumption of raw or insufficiently cooked fish was reported at prevalence rates above $75 \%$, except in children under 6 years of age (Figure 2 ).

Logistic regression was used to investigate the association of risk factors and $O$. viverrini infections at the individual level (Table 3). The analysis revealed that age, fish consumption habits, and availability of latrines were independently associated with the risk of 0 . viverrini infection. Schoolchildren aged 6 to 15 years had a 2.52-fold higher risk for an infection with $O$. viverrini than pre-school 
Table 3 Results of multivariate analysis for risk factors of Opisthorchis viverrini infection

\begin{tabular}{|c|c|c|c|}
\hline Risk factor & Odds ratio & $P$-value & $95 \% \mathrm{Cl}$ \\
\hline \multicolumn{4}{|l|}{ Age group (years) } \\
\hline$<6$ & 1.00 & & \\
\hline $6-15$ & 2.52 & 0.001 & $1.45-4.40$ \\
\hline $16-25$ & 5.60 & $<0.001$ & $2.88-1092$ \\
\hline $26-35$ & 5.84 & $<0.001$ & $3.00-11.48$ \\
\hline $36-45$ & 8.07 & $<0.001$ & $3.96-16.46$ \\
\hline $46-55$ & 12.57 & $<0.001$ & $5.18-30.50$ \\
\hline$>55$ & 9.40 & $<0.001$ & $4.52-19.56$ \\
\hline \multicolumn{4}{|l|}{ Gender } \\
\hline Female & 1.00 & & \\
\hline Male & 1.18 & 0.318 & $0.85-1.64$ \\
\hline \multicolumn{4}{|l|}{ Habit of eating raw fish } \\
\hline No & 1.00 & & \\
\hline Yes & 2.31 & $<0.001$ & $1.57-3.40$ \\
\hline \multicolumn{4}{|c|}{ Presence of any sanitation facility at home } \\
\hline $\begin{array}{l}\text { Sanitation facility } \\
\text { absent }\end{array}$ & 1.00 & & \\
\hline $\begin{array}{l}\text { Sanitation facility } \\
\text { present }\end{array}$ & 0.26 & 0.001 & $0.11-0.57$ \\
\hline \multicolumn{4}{|l|}{ Educational level } \\
\hline No formal schooling & 1.00 & & \\
\hline Primary school & 1.79 & 0.004 & $1.20-2.66$ \\
\hline $\begin{array}{l}\text { Secondary school and } \\
\text { higher }\end{array}$ & 1.02 & 0.955 & $0.54-1.91$ \\
\hline
\end{tabular}

children $(P=0.001)$. Likewise, adults aged $46-55$ years had a 12.57-fold increased risk than pre-school children $(P<0.001)$. Study participants who reported consuming raw or uncooked fish had a 2.31-fold higher risk of $O$. viverrini infection $(P<0.001)$. Having a sanitation facility in the household was associated with a $74 \%$ risk decrease (odds ratio (OR) $0.26, P=0.001$ ).

Gender did not contribute to the overall risk of infection (OR 1.18, $P=0.318$ ). Study participants with primary school educational level had a $79 \%$ increased risk for an 0 . viverrini infection (OR 1.79, $P=0.004$ ) compared with individuals with no formal schooling. People with a secondary school or higher education did not have an increased risk for an 0 . viverrini infection compared with people with no schooling (OR 1.02, $P=0.955)$.

\section{Discussion}

\subsection{Prevalence and impact of Opisthorchis viverrini}

Stool examinations show a very high endemic level of $O$. viverrini. This finding confirms the previous reports by Rim et al. (2003) in the same province and by Kobayashi et al. (2000), who showed high infection rates in the neighbouring Khammouane province. In addition, our study is most likely to underestimate infection rates. Due to time and financial constraints, only one stool sample per person could be examined. Repeated stool analysis with the Kato-Katz technique has shown to substantially increase sensitivity (de Vlas and Gryseels, 1992; Marti and Koella, 1993); hence we can assume that the 'true' prevalence may be higher than assessed in the present study.

However, misdiagnosis of $O$. viverrini by light microscopy can occur. Small intestinal trematodes such as species from the Haplorchis genus have morphologically very similar eggs. Using the Kato-Katz technique, the difference cannot be made easily, and confusion with other flukes, in particular small intestinal flukes, cannot be excluded. Haplorchis taichui and $H$. yokogawai are both endemic in Lao PDR. However, they were found at much lower prevalences than 0 . viverrini (Ditrich et al., 1990; Giboda et al., 1991a, 1991b). The clear extent, however, of their importance is not known and needs further assessment.

Opisthorchis viverrini infection is known to be a major risk factor for cholangiocarcinoma (Honjo et al., 2005). The prevalence rate of infection in Saravane district is considerably higher than recent estimates from districts of North East Thailand (Sriamporn et al., 2004), where the incidence of cholangiocarcinoma reached 302 cases per 100000 people (Sriamporn et al., 2004). In addition, recent findings suggest that $60 \%$ of the cholangiocarcinoma can be attributed to Opisthorchis infections (Honjo et al., 2005). Based on these data, and taking into account a total population of 80000 people for the district of Saravane, up to 152 cases of cholangiocarcinoma per year due to Opisthorchis infections may be expected for this district alone. This, however, is based on the assumption that no confusion was made between 0 . viverrini eggs and intestinal trematodes.

Although 0 . viverrini was observed at high prevalence rates, the intensity of infections was low, an observation that was consistently made in Thailand (Sithithaworn and Haswell-Elkins, 2003). This does not necessarily mean that the public health impact is low. The evaluation of the risk for cholangiocarcinoma performed by Honjo et al. (2005) was based on the presence of serological antibodies, and therefore even light infections and transient infections may lead to liver cancer. In our study, only two people were detected with symptoms associated with other hepatobiliar diseases such as jaundice or hepatomegaly. This agrees with earlier findings from Thailand (Pungpak et al., 1989). However, recent community-based ultrasonographic studies showed that hepatobiliar abnormalities are associated with an $O$. viverrini infection and are possible precursor conditions for cholangiocarcinoma (Elkins et al., 1996).

Our study draws attention to the sharp increase with age in infection rates, intensity of infection, and raw fish consumption, reaching a plateau in young adults. This finding suggests an accumulation of infection over time due to continuous exposure. Furthermore, no notable gender differences were seen. Comparable observations were recently made in Thailand (Sithithaworn and Haswell-Elkins, 2003).

Furthermore, our study also demonstrates a high rate of multi-helminth infections of the intestine. These infections in turn contribute to additional functional and developmental morbidity (Raso et al., 2005).

Human infection occurs through ingestion of infectious metacercaria within fish. Our investigation draws attention to the large number of different cyprinoid fish species that are consumed regularly by the Lao rural population, and also to the high rate of fish infection. This information is 
in agreement with an expert committee report put forth by WHO, in which more than 80 cyprinoid fish species are listed as potential second intermediate fish species for 0 . viverrini (WHO, 1995). Cyprinoid fish of the genera Puntius, Cyclocheilichtys and Hampala were reported to be highly infected with 0 . viverrini metacercaria (Wykoff et al., 1965), which was confirmed in our study. Unfortunately, we were not able to use the pepsin digestion technique for the metacercarial diagnosis (Tesana et al., 1985), and hence we were not able to determine the exact parasite species. Some of the fish infections may therefore also be due to other trematode infections.

Cats, dogs and rats are also definitive hosts for 0 . viverrini (Sadun, 1955). The relative contribution of these hosts to the transmission of the parasite to the intermediate snail hosts are not known but are considered minor compared with the higher egg excretion and hygiene behaviour of humans (Sadun, 1955). Estimations of infection rates in these animals have not been studied and remain unknown for Lao PDR.

\subsection{Risk factors for Opisthorchis viverrini infection}

The preference for raw and insufficiently cooked fish dishes and the low availability of sanitation facilities are the main factors contributing to a high prevalence of $O$. viverrini infection.

The overall illiteracy rate of the heads of household in our study was very high. This might be an underlying risk factor for parasitic infections. Many surveys confirm that poor educational level is significantly associated with intestinal parasitic infection. For instance, a study conducted in Iran showed that with an increased educational level of parents, the infection rates of intestinal parasites, consisting of protozoa (mainly Giardia lamblia and Blastocystis hominis) and helminths (mainly Enterobius vermicularis), declined $50 \%$ in children (Nematian et al., 2004). In our study, we could observe a trend of higher prevalence for an $O$. viverrini infection in households with a lower educational level of heads of household. However, this finding was not statistically significant.

In general, lack of sanitation is a key determinant for helminth infections. Its correlation is well documented (Esrey et al., 1991; Fewtrell et al., 2005). Our current survey shows that sanitation facilities were present in only one of 13 villages and that virtually all study participants reported defecating outdoors.

The present study describes the high endemic level of O. viverrini in the rural and remote district of Saravane in southern Lao PDR. It documents associated factors for $O$. viverrini infection, such as the consumption of raw fish and the absence of sanitation facilities. As a next step, the disease burden associated with this infection needs to be assessed at the individual and community levels to allow the design of adequate interventions. In Thailand, interventions focussing on mass treatment with praziquantel and sanitation and health education have shown to be effective (Jongsuksuntigul and Imsomboon, 2003). They might be of equal importance in areas similar to Saravane district.

\section{Conflicts of interest}

The authors have no conflicts of interest concerning the work reported in this paper.

\section{Acknowledgements}

We acknowledge the collaboration and active participation of the authorities of the Department of Provincial Health, District Health, head of villages and the people of Saravane district. This study was conducted in the framework of practical field training for a postgraduate training course offered by the Institut de la Francophonie pour la Médecine Tropicale, Vientiane, Lao PDR. The following course participants contributed to the study: Dr Touang Hong and Dr Ponha Uk. Funding was granted by Agence Universitaire de la Francophonie and Coopération pour la Recherche Universitaire et Scientifique, France (project number 02-811-052). Prof. J. Utzinger efficiently reviewed the manuscript.

\section{References}

de Vlas, S.J., Gryseels, B., 1992. Underestimation of Schistosoma mansoni prevalences. Parasitol. Today 8, 274-277.

Ditrich, O., Scholz, T., Giboda, M., 1990. Occurrence of some medically important flukes (Trematoda: Opisthorchiidae and Heterophyidae) in Nam Ngum water reservoir, Laos. Southeast Asian J. Trop. Med. Public Health 21, 482-488.

Elkins, D.B., Mairiang, E., Sithithaworn, P., Mairiang, P., Chaiyakum, J., Chamadol, N., Loapaiboon, V., Haswell-Elkins, M.R., 1996. Cross-sectional patterns of hepatobiliary abnormalities and possible precursor conditions of cholangiocarcinoma associated with Opisthorchis viverrini infection in humans. Am. J. Trop. Med. Hyg. 55, 295-301.

Esrey, S.A., Potash, J.B., Roberts, L., Shiff, C., 1991. Effects of improved water supply and sanitation on ascariasis, diarrhoea, dracunculiasis, hookworm infection, schistosomiasis, and trachoma. Bull. World Health Organ. 69, 609-621.

Fewtrell, L., Kaufmann, R.B., Kay, D., Enanoria, W., Haller, L., Colford Jr., J.M., 2005. Water, sanitation, and hygiene interventions to reduce diarrhoea in less developed countries: a systematic review and meta-analysis. Lancet Infect. Dis. 5, 42-52.

Giboda, M., Ditrich, O., Scholz, T., Viengsay, T., Bouaphanh, S., 1991a. Current status of food-borne parasitic zoonoses in Laos. Southeast Asian J. Trop. Med. Public Health 22 (Suppl.), 56-61.

Giboda, M., Ditrich, O., Scholz, T., Viengsay, T., Bouaphanh, S., 1991b. Human Opisthorchis and Haplorchis infections in Laos. Trans. R. Soc. Trop. Med. Hyg. 85, 538-540.

Haswell-Elkins, M.R., Sithithaworn, P., Elkins, D., 1992. Opisthorchis viverrini and cholangiocarcinoma in Northeast Thailand. Parasitol. Today 8, 86-89.

Honjo, S., Srivatanakul, P., Sriplung, H., Kikukawa, H., Hanai, S., Uchida, K., Todoroki, T., Jedpiyawongse, A., Kittiwatanachot, P., Sripa, B., Deerasamee, S., Miwa, M., 2005. Genetic and environmental determinants of risk for cholangiocarcinoma via Opisthorchis viverrini in a densely infested area in Nakhon Phanom, northeast Thailand. Int. J. Cancer 117, 854-860.

Jongsuksuntigul, P., Imsomboon, T., 2003. Opisthorchiasis control in Thailand. Acta Trop. 88, 229-232.

Katz, N., Chaves, A., Pellegrino, J., 1972. A simple device for quantitative stool thick-smear technique in Schistosomiasis mansoni. Rev. Inst. Med. Trop. Sao Paulo 14, 397-400.

Keiser, J., Utzinger, J., 2005. Emerging foodborne trematodiasis. Emerg. Infect. Dis. 11, 1507-1514.

Kobayashi, J., Vannachone, B., Sato, Y., Manivong, K., Nambanya, S., Inthakone, S., 2000. An epidemiological study on 
Opisthorchis viverrini infection in Lao villages. Southeast Asian J. Trop. Med. Public Health 31, 128-132.

Lun, Z.R., Gasser, R.B., Lai, D.H., Li, A.X., Zhu, X.Q., Yu, X.B., Fang, Y.Y., 2005. Clonorchiasis: a key foodborne zoonosis in China. Lancet Infect. Dis. 5, 31-41.

Mairiang, E., Mairiang, P., 2003. Clinical manifestation of opisthorchiasis and treatment. Acta Trop. 88, 221-227.

Maleewong, W., Intapan, P., Wongwajana, S., Sitthithaworn, P., Pipitgool, V., Wongkham, C., Daenseegaew, W., 1992. Prevalence and intensity of Opisthorchis viverrini in rural community near the Mekong River on the Thai-Laos border in northeast Thailand. J. Med. Assoc. Thai. 75, 231-235.

Marti, H., Koella, J.C., 1993. Multiple stool examinations for ova and parasites and rate of false-negative results. J. Clin. Microbiol. 31, 3044-3045.

Nematian, J., Nematian, E., Gholamrezanezhad, A., Asgari, A.A., 2004. Prevalence of intestinal parasitic infections and their relation with socio-economic factors and hygienic habits in Tehran primary school students. Acta Trop. 92, 179-186.

NSC, 2003. Statistical Yearbook 2003. National Statistic Centre, Vientiane, Lao PDR.

PHO, 2002. Health Statistic of Province of Saravane. Provincial Health Office, Saravane, Province of Saravane.

Pinlaor, S., Ma, N., Hiraku, Y., Yongvanit, P., Semba, R., Oikawa, S., Murata, M., Sripa, B., Sithithaworn, P., Kawanishi, S., 2004. Repeated infection with Opisthorchis viverrini induces accumulation of 8-nitroguanine and 8-oxo-7,8-dihydro-2'-deoxyguanine in the bile duct of hamsters via inducible nitric oxide synthase. Carcinogenesis 25, 1535-1542.

Pungpak, S., Sornmani, S., Suntharasamai, P., Vivatanasesth, P., 1989. Ultrasonographic study of the biliary system in opisthorchiasis patients after treatment with praziquantel. Southeast Asian J. Trop. Med. Public Health 20, 157-162.

Raso, G., Utzinger, J., Silue, K.D., Ouattara, M., Yapi, A., Toty, A., Matthys, B., Vounatsou, P., Tanner, M., N'Goran, E.K., 2005. Dis- parities in parasitic infections, perceived ill health and access to health care among poorer and less poor schoolchildren of rural Cote d'Ivoire. Trop. Med. Int. Health 10, 42-57.

Rhee, J.K., Lee, H.I., Baek, B.K., Kim, P.G., 1983. Survey on encysted cercariae of trematodes from fresh-water fishes in Mangyeong Riverside Area. Kisaengchunghak Chapchi 21, 187-192 [in Korean].

Rim, H.J., Chai, J.Y., Min, D.Y., Cho, S.Y., Eom, K.S., Hong, S.J., Sohn, W.M., Yong, T.S., Deodato, G., Standgaard, H., Phommasack, B., Yun, C.H., Hoang, E.H., 2003. Prevalence of intestinal parasite infections on a national scale among primary schoolchildren in Laos. Parasitol. Res. 91, 267-272.

Sadun, E.H., 1955. Studies on Opisthorchis viverrini in Thailand. Am. J. Hyg. 62, 81-115.

Sithithaworn, P., Haswell-Elkins, M., 2003. Epidemiology of Opisthorchis viverrini. Acta Trop. 88, 187-194.

Sriamporn, S., Pisani, P., Pipitgool, V., Suwanrungruang, K., Kamsaard, S., Parkin, D.M., 2004. Prevalence of Opisthorchis viverrini infection and incidence of cholangiocarcinoma in Khon Kaen, Northeast Thailand. Trop. Med. Int. Health 9, 588-594.

Tesana, S., Kaewkes, S., Pinlaor, S., 1985. Distribution and density of Opisthorchis viverrini metacercariae in cyprinoid fish from Khon Kaen province. J. Parasitol. Med. Assoc. Thai. 9, 21-30.

Upatham, E.S., Viyanant, V., 2003. Opisthorchis viverrini and opisthorchiasis: a historical review and future perspective. Acta Trop. 88, 171-176.

WHO, 1995. Control of foodborne trematode infections. Report of the WHO study group. World Health Organization, Geneva.

Wykoff, D.E., Harinasuta, C., Juttijudata, P., Winn, M.M., 1965. Opisthorchis viverrini in Thailand - the life cycle and comparison with 0 . felineus. J. Parasitol. 51, 207-214.

Yossepowitch, O., Gotesman, T., Assous, M., Marva, E., Zimlichman, R., Dan, M., 2004. Opisthorchiasis from imported raw fish. Emerg. Infect. Dis. 10, 2122-2126. 